\title{
Clinical Ethics and Nutrition Support
}

\author{
Denise Baird Schwartz ${ }^{*}$ MS, RD, FADA, CNSC
}

Healthcare Professional, Los Angeles, California, USA

\begin{abstract}
Nutrition support should be considered optional when this therapy is not in congruence with an individual's wishes based on quality of life goals, during the end-of-life period. Ethical dilemmas, dealing with nutrition therapy, are often due to lack of early communication between individuals, their family, and healthcare providers. Landmark young adult ethical court cases, dealing with nutrition therapy, reveal that this is not just a topic for the elderly. Healthcare literacy, multicultural populations, and different faiths add to the diversity of perspectives on healthcare decisions dealing with withholding or withdrawing nutrition therapy. These dilemmas are preventable if action steps are taken to improve the current healthcare clinical ethics model. Healthcare decision-making in advance should be considered by the individual and their family as an opportunity to communicate and plan for the future rather than a taboo topic. Healthcare facilities need to develop a proactive, integrated, structured process for healthcare ethical decision-making with measurable outcomes and shared best practice. Resources and toolkits are available to educate both the healthcare professional and the public on advance care planning.
\end{abstract}

Keywords: Clinical ethics, nutrition support, healthcare decision-making, advance care planning, end-of-life.

\section{INTRODUCTION}

Modulating nutritional therapeutics in various stages of life and disease states to improve outcomes is readily recognized. However, to withhold or withdraw nutrition therapies can result in ethical dilemmas [1]. There is a difference between delayed initiation nutrition treatment via feeding tubes (gastrointestinal tract or intravenous) in an acutely ill individual versus intentional withholding or withdrawing nutrition therapy due to a person's preferences and quality of life goals during the end-of-life period. Conflict prevention requires action. Communicating common goals focused on the individual, early before the decisionmaking process is required, may result in averting ethical dilemmas.

\section{BACKGROUND}

Clinical ethics healthcare, involving nutritional therapeutics/nutrition therapy, has evolved over the past four decades with interprofessional hospital bioethics committees, legislation promoting advance directives, palliative care team development, ethical guidelines, and ethics position and practice papers published by national healthcare organizations [2-4].

Despite these advancements, ethical dilemmas continue to occur involving life-sustaining treatments, including nutrition therapy. Lack of communication between patients and their families, and healthcare providers concerning wishes for end-of-life care and quality of life goals, before the illness and healthcare

*Address corresponding to this author at the PO Box 1770, Studio City, CA 91614, USA; Tel: 818-419-5016; E-mail: denisebairdschwartz@gmail.com

E-ISSN: 1929-5634/12 crisis, is a challenging problem. The solution to this communication deficit will be multifactorial and will require a paradigm shift by all the stakeholders [2, 4].

\section{STAKEHOLDERS AND ISSUES}

Stakeholders in this process begin with the individual and their family, and then include healthcare professionals/providers, healthcare facilities, and healthcare systems.

Baby boomers and their parents, perhaps are the first generations to face these potential ethical dilemmas, with the technology advancement in medical therapies, including nutrition therapies. Medical treatment options are available to prolong life or perhaps extend the dying process. This is not an issue only for the elderly and their adult children, but should be addressed when a person is age of majority as indicated in Figure 1. Concepts addressed include opportunity awareness communication, research options, discussion of wishes, document completion, and review and modification of decisions and documents.

Landmark adult ethical court cases, dealing with nutrition therapy, involving unfortunate individuals in their 20s, resulted in difficult situations for these young adults and their families. Although these court cases have increased awareness of the need for advance care planning, there remains a deficit in individuals documenting their wishes in writing and communicating this information for decision-making in the various healthcare facility settings [4].

Mismatched family expectations and unrealistic healthcare technology capabilities can lead to ethical 


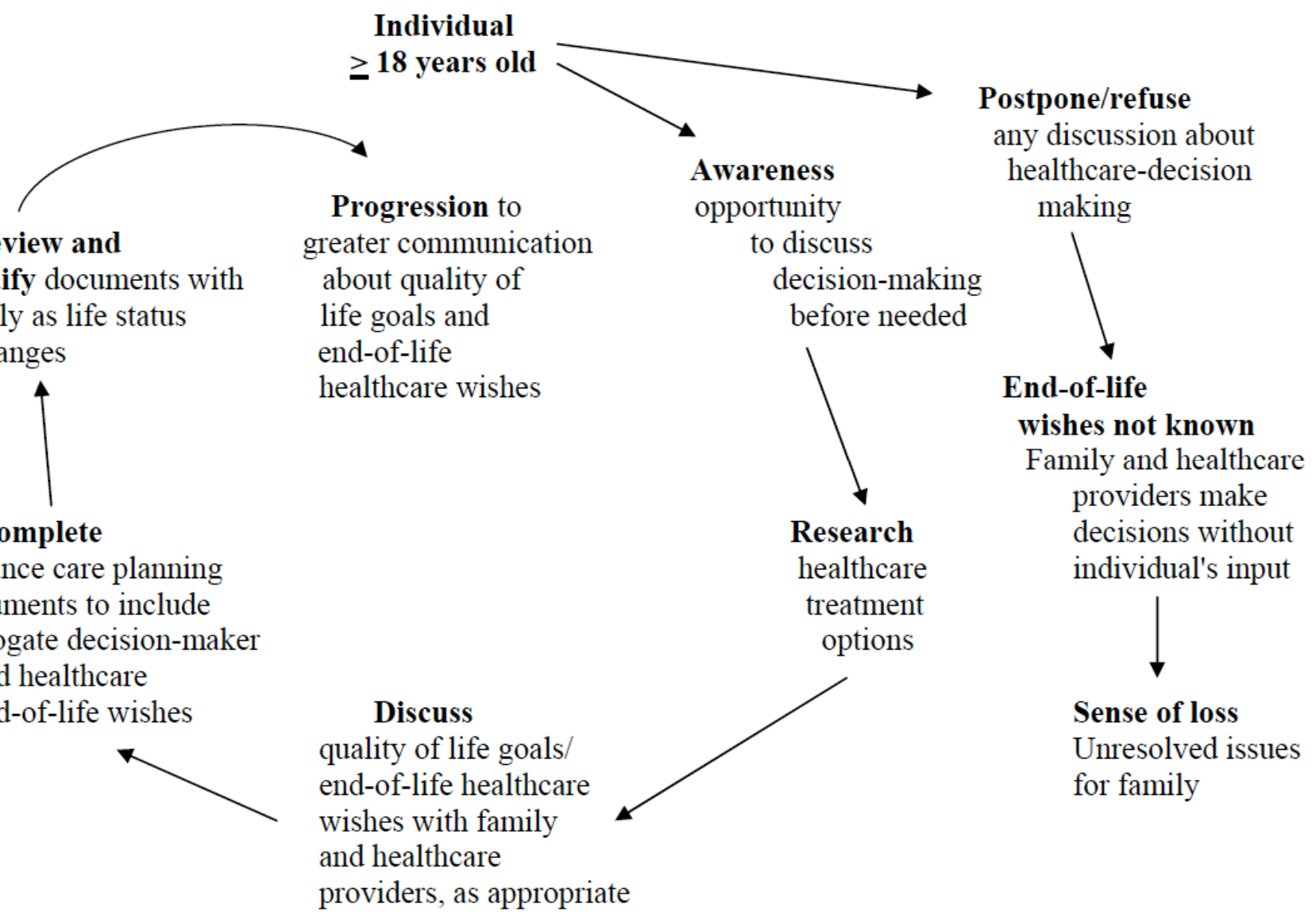

Figure 1: Cycle of healthcare decision-making for quality of life goals and end-of-life care.

conflict. Healthcare literacy, multicultural population, and different faiths further add to the diversity of concepts dealing with perspectives on an individual's illness and the decision-making process [5-8].

Nutritional therapeutics dealing with enteral and parenteral nutrition and aspects of these therapies, such as route, timing, and substrates are provided and assessed in the hospital setting. Complexities of patient wishes and quality of life goals are not always addressed. A culture change will be required involving preventive clinical ethics to improve enhanced patientcentered care based on outcome research and patient education, but requires involvement by the individual and their family [9-13].

The need for early ethical decision-making is especially evident in practice settings where timely nutrition intervention, especially critical care, is recommended to optimize healthcare outcomes. Nutrition, even administered through a tube, can provide a sense of caring. For individuals and their families these nutrition therapies become more difficult to withdraw after being initiated, than to be withheld. Individuals and their family view nutrition differently compared to healthcare professionals who recognize that artificial nutrition is a medical treatment $[2,4]$.

\section{FACILITATING EARLY COMMUNICATION}

Is it the responsibility of the individual, family or healthcare provider to start the conversation about healthcare wishes for the end-of-life? How does this question get communicated and who is responsible? Essentially these questions deal with communication at different periods and settings in one's life. Early communication before the illness or hospital healthcare crisis gives the individual the opportunity to reflect on the decision-making process, to determine options, to make decisions while not under pressure. For some individuals having this conversation after the illness starts or healthcare crisis occurs could be perceived as taking away the person's hope for a cure. Yet a realistic conversation allows the individual to express their wishes, which will be the guide to maintain patientcentered care throughout the illness.

Cultivating a culture of awareness of the benefit of this early communication is essential to open up dialogue and prevent ethical dilemmas. Figure 2 


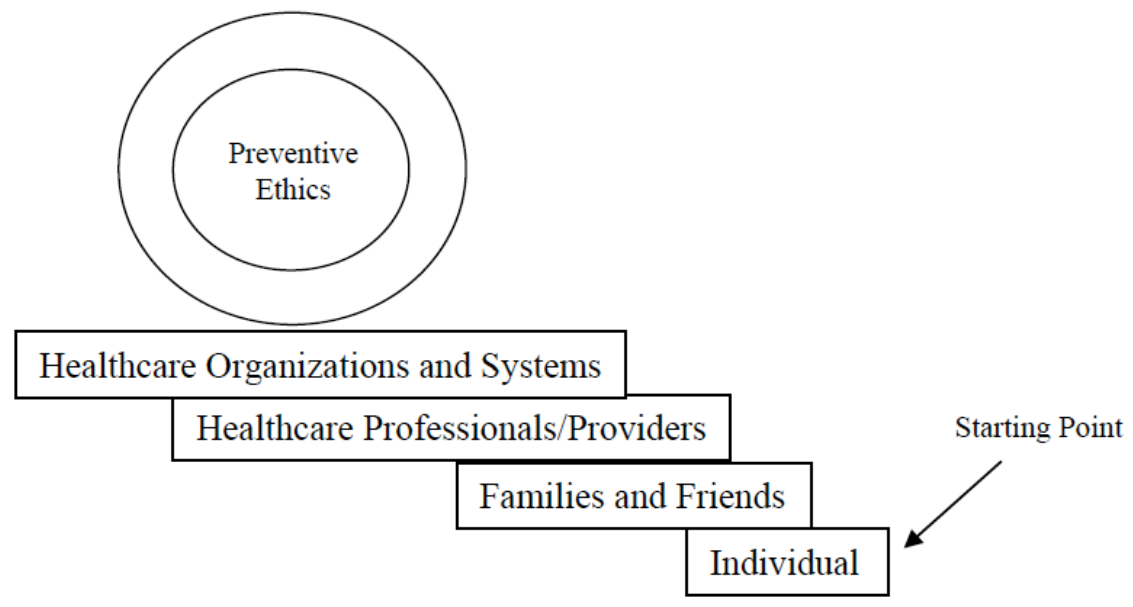

Figure 2: Building on the communication process and stepping up to the plate.

indicates the focus in this decision process should be the individual, but all stakeholders have a responsibility in bringing awareness of the problem and achieving a solution.

\section{CHANGING HEALTHCARE CLINICAL ETHICS MODEL AND PERSPECTIVE}

Asking the question "When is nutritional therapeutics optional?" causes a simple shift in perspective that opens the door for a focus on deeper concept discussion between individuals, families, and healthcare professionals/providers. Perhaps this concept is what is needed in healthcare to shift the way life is approached-deliberate and attentive to the individual's wishes. Figure $\mathbf{3}$ depicts the current healthcare clinical ethics model and how options outside the box could move this process on to a new improved model.

\section{RESOURCES AND TOOLS FOR ADVANCE CARE PLANNING}

Resources are available for healthcare providers and the public to increase knowledge in this important aspect of healthcare that would be useful when determining the appropriate use of medical therapies at a particular period in one's life.

Toolkits have been created to enhance the communication process and start the conversation. Table 2 presents sample sources for toolkits to
Proactive, Integrated, Structured Process in Healthcare Facilities

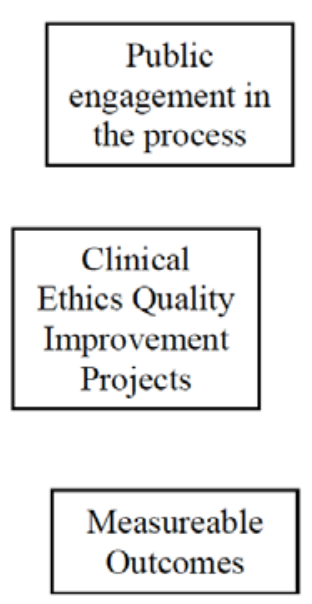

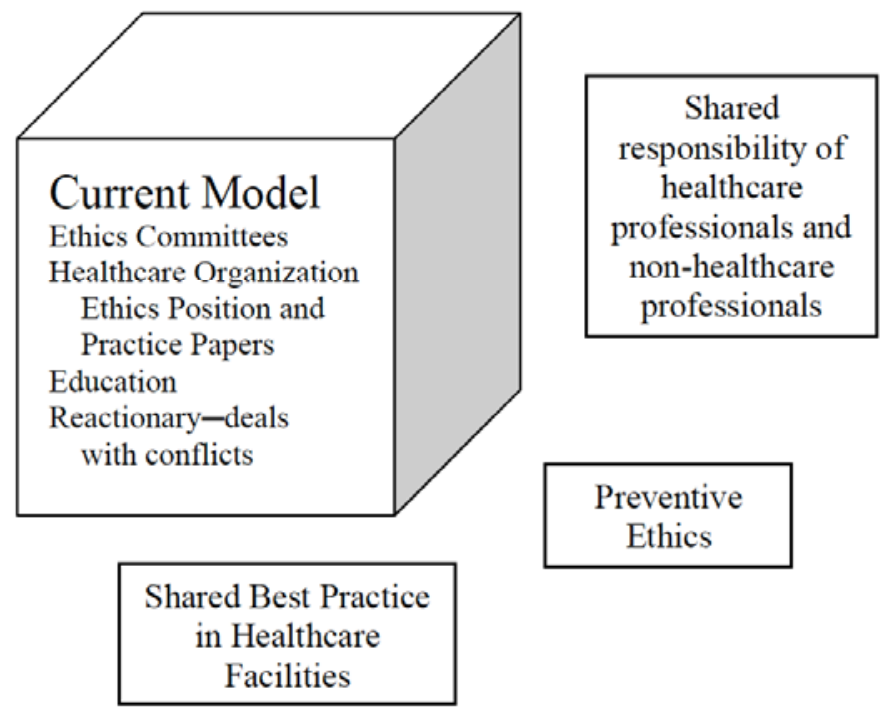

Figure 3: Changing the healthcare clinical ethics model-thinking outside the box. 
Table 1: Sample Advance Care Planning Resources [4, 14]

\begin{tabular}{|l|l|}
\hline Advance Care Planning Information Sources & \multicolumn{1}{c|}{ Focus } \\
\hline \hline $\begin{array}{l}\text { National Healthcare Decisions Day } \\
\text { www.nhdd.org }\end{array}$ & $\begin{array}{l}\text { Goal to inspire, educate and empower the public and providers about the importance of } \\
\text { advance care planning } \\
\text { Provides specific resources for activities to promote National Healthcare Decisions Day } \\
\text { Held annually April 16 }\end{array}$ \\
\hline $\begin{array}{l}\text { Physician Orders for Life-Sustaining Treatment } \\
\text { (POLST) } \\
\text { www.polst.org }\end{array}$ & $\begin{array}{l}\text { Paradigm program designed to improve the quality of care people receive at end-of-life } \\
\text { Based on effective communication of patient wishes, documentation of medical orders on } \\
\text { a brightly colored form and a promise by healthcare professionals to honor these wishes }\end{array}$ \\
\hline
\end{tabular}

Table 2: Advance Care Planning Toolkits [4, 14]

\begin{tabular}{|l|l|}
\hline $\begin{array}{l}\text { The Conversation Project } \\
\text { www.theconversationproject.org }\end{array}$ & $\begin{array}{l}\text { Provides Starter Kit to help gather thoughts on the process and then have conversations } \\
\text { with a loved one on wishes for end-of-life care } \\
\text { Goal to have every person's end-of-life preferences expressed and respected }\end{array}$ \\
\hline $\begin{array}{l}\text { Five Wishes - Aging With Dignity } \\
\text { www.agingwithdignity.org/five-wishes.php }\end{array}$ & $\begin{array}{l}\text { Helps start and structure important conversations about care } \\
\text { Useful guide and documentation tool of individual's wishes }\end{array}$ \\
\hline $\begin{array}{l}\text { Speak Up campaign } \\
\text { www.advancecareplanning.ca }\end{array}$ & $\begin{array}{l}\text { Speak Up Campaign Kit contains material to promote advance care planning } \\
\text { Campaign to promote advance care planning in Canada } \\
\text { Developed to raise awareness of importance of advance care planning and end-of-life } \\
\text { care }\end{array}$ \\
\hline
\end{tabular}

promote concepts that help individuals and their family better understand advance care planning.

\section{ENGAGING THE PUBLIC IN THE PROCESS}

The importance of starting the conversation by individuals and family to prevent the clinical ethics healthcare dilemmas is essential for the individual to remain in control, as much as possible, during the healthcare decision-making process. Engaging the public in the process with early communication remains a key to preventing ethical dilemmas. Breathe by Anne Bland is an example of a book written by a healthcare professional, under a pen name, about a true powerful story to help individuals begin dialogue with family members about end-of-life healthcare decisions [15]. Intended for both the non-healthcare professional and the healthcare clinician, to serve as a personal example of how intertwining intimate stories dealing with family relationships, faith, and values can be a tool to start these sensitive conversations.

Figure 4 shows that advance care planning should be considered an opportunity for planning rather than a taboo topic.

\section{CONCLUSION}

Nutrition therapy ethical dilemmas remain an ongoing problem with various stakeholders and issues to be addressed. Lack of early communication about quality of life goals and end-of-life care is at the center of these ethical dilemmas. Resources and toolkits are available for educating individuals, family, and healthcare professionals seeking this information. Engaging the public in this topic is essential to improve patient-centered outcomes and achieve preventive ethics.

\begin{tabular}{|cc|} 
Taboo topic & $\begin{array}{c}\text { Opportunity to } \\
\text { Communicate }\end{array}$ \\
Avoidance & $\begin{array}{c}\text { Dealing with } \\
\text { Reality } \\
\text { Fear } \\
\text { Planning for the } \\
\text { Future }\end{array}$ \\
\hline
\end{tabular}

Figure 4: Changing the public's perspective on advance care planning.

\section{REFERENCES}

[1] Barrocas A, Geppert G, Durfee SM, et al. A.S.P.E.N. Board of Directors. A.S.P.E.N. Ethics Position Paper. Nutr Clinc Prac 2010; 25: 672-79. http://dx.doi.org/10.1177/0884533610385429

[2] Geppert CMA, Barrocas A, Schwartz DB. Ethics and Law. In: Mueller C, McClave SA, Schwartz DB, Kovacevich D, Miller S, Eds. The A.S.P.E.N. Adult Nutrition Support Core Curriculum, $2^{\text {nd }}$ ed. Springfield, MD: American Society for Parenteral and Enteral Nutrition 2012; pp. 656-676.

[3] Mittleman LR. The legal implications of withholding and withdrawing nutrition support. Support Line 1992; 14: 1-5. 
[4] Schwartz DB. Ethical Considerations in the Critically III Patient. IN: Cresci G, Ed. Nutritional Therapy for the Critically III Patient: A Guide to Practice $2^{\text {nd }}$ ed. Boca Raton, FL: Taylor \& Francis 2013; (in press).

[5] Carbone ET, Zoellner JM. Nutrition and health literacy: a systematic review to inform nutrition research and practice. $J$ Acad Nutr Diet 2012; 112: 254-65. http://dx.doi.org/10.1016/j.jada.2011.08.042

[6] Weiss BD. Health Literacy and Patient Safety: Help Patients Understand Manual for Clinicians. Second edition, American Medical Association Foundation, 2007; (www.ama-assn. org/ama1/pub/upload/mm/367/healthlitclinicians.pdf).

[7] Preedy VR, Ed. Diet and Nutrition in Palliative Care. Boca Raton, FL:CRC Press 2011.

[8] Searight HR, Gafford J. Cultural diversity at the end of life: issues and guidelines for family physicians. Am Fam Physician 2005; 71: 515-22.

[9] Epstein EG. Preventive ethics in the intensive care unit. Am Assoc Crit Care Nurs 2012; 23: 217-24. http://dx.doi.org/10.1097/NCl.0b013e31824b3b9b
[10] Gabriel SE, Normand ST. Getting the methods right-the foundation of patient-centered outcomes research. New Eng J Med 2012; 367: 787-90. http://dx.doi.org/10.1056/NEJMp1207437

[11] Barry MJ, Edgman-Levitan S. Shared decision making-the pinnacle of patient-centered care. N Engl J Med 2012; 366: 780-81. http://dx.doi.org/10.1056/NEJMp1109283

[12] Reuben DB, Tinetti ME. Goal-oriented patient care-an alternative health outcomes paradigm. N Engl J Med 2012; 366: 777-79.

http://dx.doi.org/10.1056/NEJMp1113631

[13] Gallagher-Allred CR. Communication and education for families dealing with end-of-life decisions. J Acad Nutr Diet 2012; 112: 309-10. http://dx.doi.org/10.1016/j.jand.2011.12.019

[14] Schwartz DB. Three Steps for Improving End-of-Life Nutrition Care. Clin Nutr Insight 2012; 38: 4-5.

[15] Bland A. Breathe-A True Story of Letting Go of My Parents Gracefully, For I Will See Them Again. Bloomington, IN:Xlibris, 2009. www.breath-annebland.com

Received on 12-09-2012

Accepted on 09-10-2012

Published on 16-10-2012

DOI: http://dx.doi.org/10.6000/1929-5634.2012.01.01.9

(C) 2012 Denise Baird Schwartz; Licensee Lifescience Global.

This is an open access article licensed under the terms of the Creative Commons Attribution Non-Commercial License (http://creativecommons.org/licenses/by-nc/3.0/) which permits unrestricted, non-commercial use, distribution and reproduction in any medium, provided the work is properly cited. 